\title{
A TRAJETÓRIA DA PRODUÇÃO ACADÊMICO-CIENTÍFICA DO CURSO TÉCNICO EM CONTROLE AMBIENTAL DO CEFET-RN: 2002-2004
}

\author{
Régia Lúcia Lopes ${ }^{1}$, Vanda Maria Saraiva ${ }^{2}$ e Valdenildo Pedro da Silva ${ }^{3}$ \\ ${ }^{1}$ Professora do CEFET-RN, Mestre em Engenharia Química \\ rlucia@cefetrn.br \\ ${ }^{2}$ Professora do CEFET-RN, Mestre em Genética \\ adnav@cefetrn.br \\ ${ }^{3}$ Professor do CEFET-RN, Doutor em Geografia \\ valdenildo@cefetrn.br
}

Recebido em fevereiro de 2006 e aceito em maio de 2006

\section{RESUMO}

O meio ambiente tem se tornado uma das grandes preocupações de todas as comunidades do nosso Planeta nos últimos tempos, seja pelas alterações provocadas pela ação do homem na natureza, seja pela resposta que esta dá a essas alterações. Em nosso País, o Ministério da Educação, mostrando-se preocupado com as questões ambientais, criou em 2000 a área profissional de meio ambiente entre outras, pois entendia ser necessária a formação de profissionais que buscassem resolver com eficiência problemas ambientais, no sentido de promover a sustentabilidade ambiental. Essa proposição era uma das funções sociais do Centro Federal de Educação Tecnológica do Rio Grande do Norte (CEFET-RN), com a oferta do curso técnico de Tecnologia Ambiental e, que a partir de 2001, seguindo as novas diretrizes da educação profissional, passou a denominar-se Curso Técnico em Controle Ambiental, se estruturando com as funções de reconhecimento, avaliação e gerenciamento das questões ambientais. Desde então, esse curso passou a ter como propósito a implementação de projetos de investigação acadêmico-científica, envolvendo temáticas tais como: resíduos sólidos, educação ambiental, impacto ambiental, marketing ambiental, qualidade das águas, legislação ambiental, tratamentos de esgotos, estudos de fauna e flora, dentre outras. O estudo em pauta se propõe a apresentar um panorama dessa produção acadêmica, a partir da análise de 28 monografias apresentadas e defendidas pelos alunos, durante o período de 2002 a 2004. Objetiva, ainda, desenvolver uma análise de temáticas referenciadas pelas próprias pesquisas, destacando as principais contribuições expressas nesses trabalhos técnicos para as questões ambientais locais e regionais. 


\section{A TRAJETÓRIA DA PRODUÇÃO ACADÊMICO-CIENTÍFICA DO CURSO TÉCNICO EM CONTROLE AMBIENTAL DO CEFET-RN: 2002-2004}

\section{INTRODUÇÃO}

O presente estudo tem por finalidade apresentar um breve panorama da produção acadêmico-científica do curso técnico em Controle Ambiental do Centro Federal de Educação Tecnológica do Rio Grande do Norte (CEFET-RN), no período de 2002 a 2004. Objetiva, ainda, analisar as temáticas ambientais contempladas pelas pesquisas realizadas no decorrer desse período.

Inicialmente, pode-se dizer que o meio ambiente tem se tornado uma das grandes preocupações de todas as populações mundiais no curso dos últimos anos, seja pelas alterações proporcionadas pela ação humana sobre a natureza, seja pela resposta que esta dá a essas alterações. A problemática do meio ambiente surgiu como um fenômeno politicamente significativo no contexto dos preparativos para a Conferência de Stockholm, nos idos de 1970. Desde esse momento, os desafios colocados pelo acúmulo de evidências das realidades geográficas multiescalares sobre os limites do crescimento material em nível global vêm articulando de maneira gradativa a atenção das comunidades científicas, gestores públicos, alguns segmentos empresariais e demais setores organizados da sociedade civil em praticamente todos os países (HOGAN; VIEIRA, 1995). Outros eventos têm ocorrido, no curso dos últimos tempos, preocupados com as questões ambientais. Um dos recentes eventos que esteve preocupado com a problemática ambiental foi a Conferência Internacional Rio-92 no Brasil, que contou com a participação de mais de 170 países.

No Brasil, o Ministério da Educação (MEC) criou em 2000 a área profissional de meio ambiente dentre outras (BRASIL, 2000), pois entendia ser necessária a formação de profissionais que buscassem soluções para os problemas ambientais em suas múltiplas dimensões, ${ }^{1}$ almejando com isso a promoção da sustentabilidade ambiental (SACHS, 2000).

Essa preocupação, por sua vez, já se constituía em parte da função social do CEFET-RN, pois, mesmo antes de existir a área profissional de Meio Ambiente no MEC, a Instituição dispunha de um curso técnico em Tecnologia Ambiental que era dividido em três habilitações: Controle Ambiental, Controle Sanitário e Controle de Águas (ETFERN, 1995).

A partir de 2001, o CEFET-RN, unificando essas habilitações tendo em vista a nova formatação de cursos, cria o curso técnico em Controle Ambiental (seguindo as novas diretrizes da educação profissional estabelecidas pelo Decreto $n^{\circ} 2.208 / 1997$ ), que passou a formar profissionais capazes de atuar nas funções de reconhecimento, avaliação e gerenciamento dos problemas ambientais.

A equipe pesquisadora do estudo em pauta, preocupada com a não sistematização das pesquisas realizadas pelos cursos técnicos da Instituição, passou a fazer um levantamento dos trabalhos que vêm sendo desenvolvidos pela área profissional de meio ambiente,

\footnotetext{
${ }^{1}$ Estas compreendem as dimensões social, cultural, ecológica, ambiental, territorial, econômica e política.
} 
procurando estabelecer o significado e a importância destes para as realidades local e regional, bem como fornecer importante suporte analítico para formulação de estratégias necessárias à melhoria do meio ambiente.

\section{METODOLOGIA}

Para a realização dessa pesquisa, partiu-se, inicialmente, do entendimento de meio ambiente como habitat socialmente criado, configurado enquanto um meio físico modificado pela ação humana (JACOBI, 1999). E as questões ambientais como sendo resultantes de um relacionamento diferenciado entre os homens e a natureza. A metodologia usada para esta investigação científica está apoiada em alguns suportes teóricos, seguindo uma experiência de Megid Neto (1999) e em dados secundários coletados junto à coordenação do Curso Técnico de Controle Ambiental do CEFET-RN. À vista do acima exposto e dos objetivos propostos, a pesquisa utilizou os seguintes procedimentos: levantamento bibliográfico sobre o tema meio ambiente; levantamento junto a Secretaria da Gerência Educacional de Recursos Naturais (GERN) dos trabalhos apresentados e defendidos pelos alunos-técnicos; classificação das pesquisas em focos temáticos e ano de apresentação; tratamento, análise e interpretação das informações levantadas. Após a coleta dos dados fez-se uma análise e interpretação dos mesmos, bem como sua articulação com as discussões teóricas pertinentes ao assunto, procedendo-se, em seguida, à elaboração deste texto.

\section{ANÁLISE DA INFORMAÇÃO COLETADA E RESULTADOS ALCANÇADOS}

Conforme mencionado anteriormente, desde o ano de 2001, o CEFET-RN vem formando novos profissionais na área de Meio Ambiente. Com uma nova matriz curricular, o curso de Controle Ambiental estruturou-se sob a forma de módulos, sendo o primeiro denominado de Básico (núcleo comum e introdutório a outros cursos da Área Profissional de Meio Ambiente e centrado no conhecimento das ciências ambientais); o segundo, Módulo 1, de Avaliação de Impactos Ambientais (contempla os conhecimentos voltados para a identificação e avaliação dos problemas ambientais); e o último, Módulo 2, de Gerenciamento Ambiental (compreende os conhecimentos de legislação, gestão e uso de tecnologias de controle ambientais.

Com a implementação do novo curso, a formação do técnico em Controle Ambiental passou a contemplar a prática profissional diferente da anteriormente desenvolvida que só considerava o estágio supervisonado. Dessa feita, a nova metodologia de trabalho passou a envolver, além do estágio, projetos de pesquisa. Essa prática profissional passou a ser realizada por meio de projetos interdisciplinares com desenvolvimento de pesquisas técnico-científicas sobre questões e/ou problemas ambientais ou em um estágio supervisionado em Instituições públicas e privadas. Anteriormente, não era realizada nenhuma pesquisa ambiental, em caráter acadêmico-científico, por parte dos alunos, portanto essa metodologia de trabalho passou a ocorrer depois da implementação desse novo currículo.

Na pesquisa foram levantados 28 trabalhos de estudos, apresentados e defendidos por alunos desse curso técnico e que envolvem questões ambientais. Esses trabalhos foram realizados de maneira coletiva pelos estudantes, sistematizados em grupos com número variável de 2 a 5 pesquisadores, contando com orientação e acompanhamento do corpo docente do curso. Para a obtenção do diploma de conclusão de curso técnico, os trabalhos 
foram apresentados a uma banca composta por no mínimo 3 professores da área de Recursos Naturais, finalizando assim a avaliação dos alunos.

Os resultados obtidos por meio do levantamento, sistematização e análise da produção acadêmico-científica dos alunos do curso técnico em Controle Ambiental do CEFET-RN estão indicados no Quadro 1 e nas interpretações realizadas pela equipe pesquisadora.

Esta pesquisa visa oferecer aos demais alunos do curso e interessados com a temática ambiental um conjunto de aspectos que têm caracterizado as tendências ou trajetórias da pesquisa sobre o meio ambiente, no âmbito do CEFET-RN entre 2002 e 2004. Apresenta as tendências, os temas estudados, os métodos empregados, possibilitando outras investigações sobre a área ambiental.

A partir dos trabalhos listados no Quadro 1, pode-se constatar que as temáticas consideradas e questionadas pelos alunos procuraram estar em sintonia com os encaminhamentos do novo currículo do curso ou em sintonia com as funções e sub-funções propugnadas para o curso de Controle Ambiental da área profissional de Meio Ambiente.

Quadro 1 - Pesquisas realizadas no curso técnico de Controle Ambiental do CEFET-RN: 2002-2004.

\begin{tabular}{|l|c|c|}
\hline \multicolumn{1}{|c|}{ Título do Trabalho } & Focos Temáticos & Ano \\
\hline $\begin{array}{l}\text { Avaliação da Eficiência da ETE* dos } \\
\text { Resíduos Industriais da AMBEV-Natal }\end{array}$ & Tratamento de efluentes & 2002 \\
\hline $\begin{array}{l}\text { Levantamento Florístico e Faunístico do } \\
\text { Assentamento José Coelho da Silva }\end{array}$ & Diagnóstico Ambiental & 2002 \\
\hline $\begin{array}{l}\text { Otimização do Sistema de Aeração da ETE } \\
\text { da UFRN }\end{array}$ & Tratamento de Efluentes & 2002 \\
\hline $\begin{array}{l}\text { A Política Ambiental: um Instrumento de } \\
\text { Gerenciamento Ambiental no Condomínio } \\
\text { Residencial Green Woods }\end{array}$ & Legislação Ambiental & 2002 \\
\hline $\begin{array}{l}\text { Determinação da Taxa de Degradação de } \\
\text { Efluentes nas ETE’s de Ponta Negra e da } \\
\text { UFRN }\end{array}$ & Tratamento de efluentes & 2002 \\
\hline $\begin{array}{l}\text { Meio Ambiente e Qualidade de Vida: um } \\
\text { Enfoque do Ponto de Vista do Saneamento } \\
\text { Básico no Bairro de Ponta Negra- Natal }\end{array}$ & Diagnóstico Ambiental & 2002 \\
\hline $\begin{array}{l}\text { Principais Mecanismos Legais de Proteção } \\
\text { Ambiental }\end{array}$ & Legislação Ambiental & 2002 \\
\hline $\begin{array}{l}\text { Caracterização dos Resíduos Sólidos no } \\
\text { Condomínio Green Woods }\end{array}$ & Resíduos Sólidos & 2002 \\
\hline $\begin{array}{l}\text { Projeto Ação em Educação Ambiental no } \\
\text { Assentamento José Coelho da Silva }\end{array}$ & Educação Ambiental & 2002 \\
\hline Cidade Verde: Ocupação do Solo Urbano & Diagnóstico Ambiental & 2002 \\
\hline Avaliação da Coleta Seletiva em Natal & Resíduos Sólidos & 2002 \\
\hline $\begin{array}{l}\text { Estudo da Viabilidade da Utilização do Peixe } \\
\text { Branchydanio Rerio Como Possível } \\
\text { Indicador de Toxicidade de Efluentes } \\
\text { Industriais }\end{array}$ & Qualidade das Águas & 2002 \\
\hline $\begin{array}{l}\text { Avaliação do Projeto de Coleta Seletiva do } \\
\text { CEFET-RN Aspectos relacionados a }\end{array}$ & Resíduos Sólidos & 2002 \\
\hline
\end{tabular}




\begin{tabular}{|c|c|c|}
\hline $\begin{array}{lllll}\text { sistemática de } & \text { operação e educação } \\
\text { Ambiental } & & & \\
\end{array}$ & & \\
\hline $\begin{array}{l}\text { Avaliação do processo de vermi- } \\
\text { compostagem do CEFET-RN }- \text { Aspectos } \\
\text { técnicos de execução e monitoramento }\end{array}$ & Resíduos Sólidos & 2002 \\
\hline $\begin{array}{l}\text { Diagnóstico dos resíduos sólidos gerados em } \\
\text { postos de gasolina de Natal - Zona Sul e } \\
\text { Oeste }\end{array}$ & Resíduos Sólidos & 2002 \\
\hline $\begin{array}{l}\text { Diagnóstico dos resíduos sólidos gerados em } \\
\text { postos de gasolina de Natal - Zona Norte e } \\
\text { Leste }\end{array}$ & Resíduos Sólidos & 2002 \\
\hline $\begin{array}{l}\text { Diagnóstico Ambiental dos municípios de } \\
\text { Açu, Cruzeta e Acari/RN }\end{array}$ & Diagnóstico Ambiental & 2002 \\
\hline $\begin{array}{l}\text { Levantamento da fauna e flora do Rio } \\
\text { Golandim }\end{array}$ & Diagnóstico Ambiental & 2002 \\
\hline $\begin{array}{lllll}\text { Avaliação Ambiental da } & \text { Via Costeira - } \\
\text { Natal/RN } & & & & \end{array}$ & Diagnóstico Ambiental & 2003 \\
\hline $\begin{array}{l}\text { Diagnóstico dos Resíduos Sólidos nas Feiras: } \\
\text { Alecrim, Rocas, Carrasco e Cidade da } \\
\text { Esperança - Natal/RN }\end{array}$ & Resíduos Sólidos & 2003 \\
\hline $\begin{array}{l}\text { Análise bacteriológica e Helminto-lógica em } \\
\text { Águas Residuais Tratadas pelo Reuso em } \\
\text { Irrigação }\end{array}$ & Tratamento de Efluentes & 2003 \\
\hline $\begin{array}{l}\text { Caracterização e Diagnóstico de Impactos } \\
\text { Ambientais no Rio Doce, entre Natal e } \\
\text { Extremoz-RN }\end{array}$ & Impacto Ambiental & 2003 \\
\hline $\begin{array}{l}\text { Estudo de Impacto ambiental na Área de } \\
\text { Disposição dos Resíduos Sólidos no Bairro } \\
\text { Maruim e Sítio Rendeira - Macau/RN }\end{array}$ & Impacto Ambiental & 2003 \\
\hline $\begin{array}{l}\text { Marketing Ambiental e sua Influencia } \\
\text { Educacional ao Consumidor tendo em vista o } \\
\text { Desenvolvimento sustentável }\end{array}$ & Marketing Ambiental & 2003 \\
\hline $\begin{array}{l}\text { Coleta Seletiva: uma Visão Panorâmica do } \\
\text { programa no Bairro de Capim Macio }\end{array}$ & Resíduos Sólidos & 2003 \\
\hline $\begin{array}{l}\text { Diagnóstico dos Espaços Vazios na Vila de } \\
\text { Ponta Negra em Natal/RN }\end{array}$ & Diagnóstico Ambiental & $\begin{array}{c}2004 \\
\text { continuação }\end{array}$ \\
\hline $\begin{array}{l}\text { Remoção de Algas do Efluente da ETE de } \\
\text { Ponta Negra por meio de Processos Físico- } \\
\text { Químicos. }\end{array}$ & Tratamento de Efluentes & 2004 \\
\hline $\begin{array}{l}\text { Diagnóstico ambiental de uso e ocupação do } \\
\text { solo de um trecho das margens do Rio Doce } \\
\text { na comunidade África - Natal/RN } \\
\text { Nota: *Estação de Tratamento de Esgotos }\end{array}$ & Diagnóstico Ambiental & 2004 \\
\hline
\end{tabular}

A partir dos trabalhos listados no Quadro 1, pode-se constatar que as temáticas consideradas e questionadas pelos alunos procuraram estar em sintonia com os encaminhamentos do novo currículo do curso ou em sintonia com as funções e sub-funções propugnadas para o curso de Controle Ambiental da área profissional de Meio Ambiente. 
A produção científica esteve voltada para as questões do meio ambiente local e regional, principalmente para os problemas dos resíduos sólidos, qualidade das águas, tratamento de efluentes, diagnóstico ambiental, educação ambiental, impacto ambiental, marketing ambiental e legislação ambiental, conforme mostrado na Figura 1.

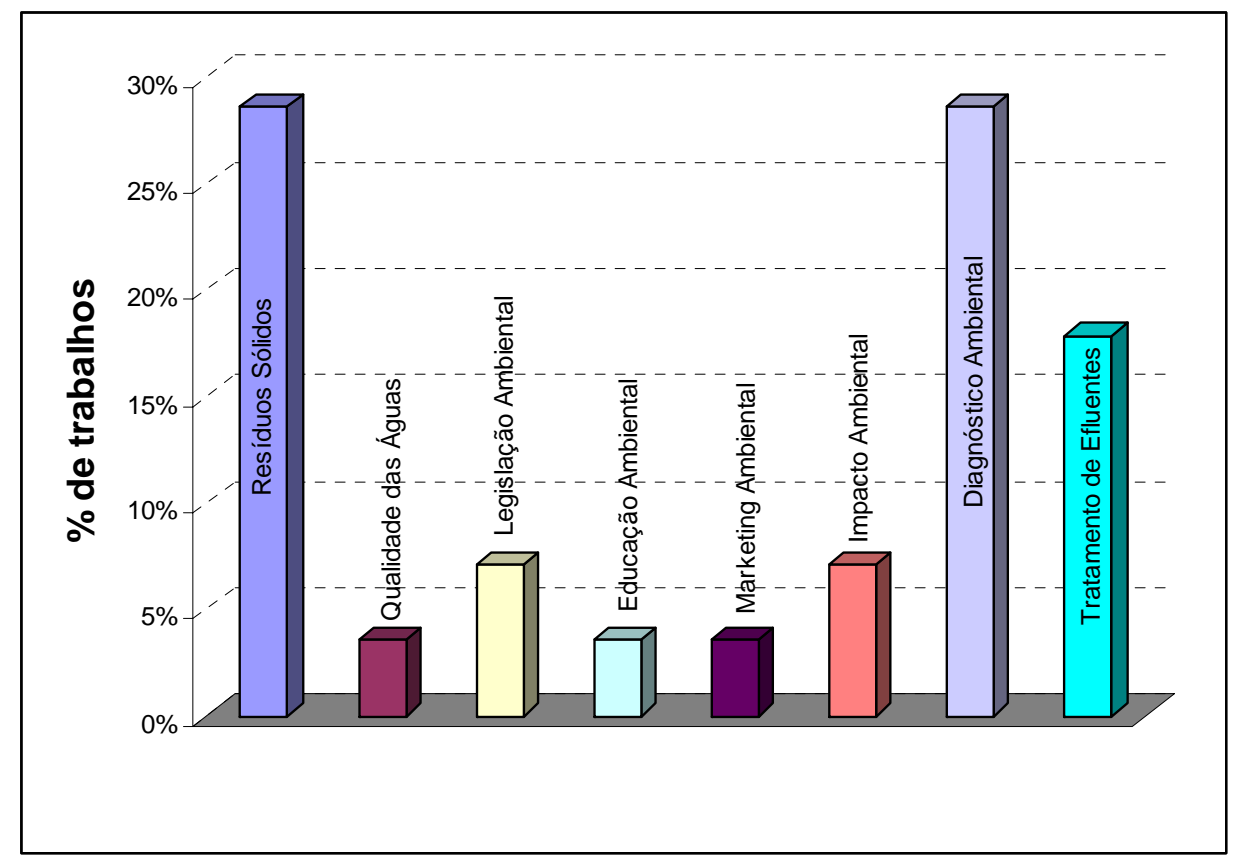

Figura 1 - Tendência dos temas dos trabalhos realizados.

Predominaram nas pesquisas realizadas as temáticas relacionadas com os resíduos sólidos, tratamento de efluentes e diagnósticos ambientais. Essas temáticas corroboram com as principais questões vivenciadas em nossa região, quais sejam, o problema da falta de destinação adequada para os resíduos sólidos e suas formas de gestão e o tratamento de efluentes, assim como a necessidade de diagnósticos ambientais que embasem projetos dos órgãos gestores a serem executados para a melhoria do meio ambiente.

Esses trabalhos não apresentam um aprofundamento teórico-empírico, em virtude do grau de ensino em que se encontram os alunos, mas podem ser considerados como ensaios científicos de suma importância pela riqueza de informações e de dados pesquisados. Muitos dessas pesquisas têm apresentado conclusões e soluções importantes para resolver os problemas investigados, contribuindo para melhorar a qualidade do meio ambiente local e regional.

Na área de resíduos sólidos podemos citar os estudos de avaliação da coleta seletiva na cidade de Natal, que subsidiaram tomadas de decisão pela empresa que gerencia os serviços na cidade. Com relação as investigações sobre gerenciamento dos diversos tipos de resíduos gerados no CEFET-RN, muitas ações foram implementadas a partir dos diagnósticos realizados, tais como melhoria no processo de acompanhamento da vermicompostagem, implementação de locais pra disposição adequada de resíduos de serviços de saúde e de resíduos a espera da coleta convencional.

No tocante aos diagnósticos e análises de uso e ocupação do solo, as pesquisas têm contribuído para constatar que os parâmetros físico-químicos e biológicos de corpos 
d’água, do solo urbano, resquícios de cobertura vegetal, saúde, qualidade de vida são modificados por uso inadequado, contribuindo dessa forma para geração de impactos ambientais.

No geral, esses estudos têm feito recomendações ao poder público e a própria sociedade, no sentido de minimizar os impactos ambientais decorrentes desses usos inadequados. Dessa forma, os trabalhos têm sinalizado com ações que primam com uma gestão racional do meio ambiente como pensa Bressan (1996).

\section{CONCLUSÕES}

O CEFET-RN atua em uma das dimensões que pode contribuir para a melhoria do meio ambiente, na medida em que tem formado profissionais capazes de atuar no diagnóstico e controle dos problemas ambientais.

Os trabalhos apresentados e defendidos pelos alunos do curso técnico em Controle Ambiental pelas turmas dos anos de 2002 a 2004 têm tido repercussão durante o percurso de formação dos alunos, e proporcionado a aquisição de novos conhecimentos além dos sistematizados em sala de aula, favorecendo ao desenvolvimento de habilidades e competências importantes para a formação do técnico de nível médio.

Com o desenvolvimento da pesquisa é possível observar que houve um incremento na independência intelectual dos alunos uma vez que os mesmos demonstraram competências em articular teoria e prática e domínio das habilidades tais como: trabalho em equipe, elaboração de instrumentos de coleta de dados, aplicação de instrumentos de pesquisa em órgãos públicos e privados e comunidade em geral além de ações em laboratórios. Todas essas atividades foram desenvolvidas de forma independente, com autonomia na busca dos temas, pesquisa e organização das atividades e finalmente da elaboração dos trabalhos em formas de monografias.

Isso demonstra o desenvolvimento de formação sólida do técnico com uma postura ética, responsabilidade social, visão crítica global e atualizada do mundo e consciência solidária dos problemas ambientais de seu tempo-espaço. Desta forma, pode-se dizer que a função social da Instituição tem sido cumprida pela promoção de uma educação científicotecnológico-humanística, visando à formação integral do profissional-cidadão críticoreflexivo, competente técnica e eticamente e comprometido efetivamente com as transformações sociais, políticas e culturais de sua comunidade.

\section{REFERÊNCIAS}

BRASIL. Ministério da Educação. Educação profissional: referenciais curriculares nacionais da educação profissional de nível técnico. Brasília: MEC, 2000.

BRESSAN, Delmar. Gestão racional da natureza. São Paulo: Hucitec, 1996.

ETFRN. Escola Técnica Federal do Rio Grande do Norte. Proposta Curricular. Revista da ETFRN, n. 9, ano 11, Natal, jan. 1995.

HOGAN, Daniel; VIEIRA, Paulo (Org.). Dilemas socioambientais e desenvolvimento sustentável. Campinas-SP: Ed. Da Unicamp, 1995. 
JACOBI, Pedro. Cidade e meio ambiente: percepções e práticas em São Paulo. São Paulo: ANNABLUME, 1999.

MEGID NETO, Jorge. Tendências da pesquisa acadêmica sobre o ensino de ciências no nível fundamental. Campinas-SP. 1999. Tese (Doutorado em Educação) Universidade Estadual de Campinas.

SACHS, Ignacy. Caminhos para o desenvolvimento sustentável. Rio de Janeiro: Garamond, 2000. 